\title{
Masa Tenisi Çok Top Antrenmanının 9-12 Yaş Grubu Çocuklarda Görsel Reaksiyon Performansındaki Etkisinin İncelenmesi
}

\begin{abstract}
Yakup KAYA*
Adil Deniz DURU ${ }^{* *}$

$\ddot{\mathbf{O z}}$

Görsel dikkat çevremizde gerçekleşen olaylara olan farkındalığımız ile ilişkilidir. Görsel dikkat bilginin seçimini gerektirdiği için, dikkatin yüksek olması olaylara verdiğimiz reaksiyonların ivedileşmesinde önemli rol oynamaktadır. Sportif faaliyetlerde, görsel dikkatin, doğrudan performansa etki edeceği açıktır. Görsel dikkatin yüksek olması, planlanan hareketin doğru ve hızlı gerçekleştirilmesine etki eder. Bu çalışma kapsamında, masa tenisi sporuna başlamamış iki grup, hazırlanan bir görsel dikkat paradigması ile test edilmiştir. Gruplardan birine masa tenisi Eğitimi verilmiş, diğer gruba eğitim uygulanmamıştır. Antrenman programı 12 hafta boyunca haftada 3 gün uygulanmıştır. Antrenmanlar sonunda son ölçümler gerçekleştirilmiş ve katılımcıların paradigmaya verdikleri yanıtlar analiz edilmiştir. Paradigma, elle atılan hızlı ve yavaş servislerin videolarını ve robot tarafından atılan servislerin video uyaranları olarak belirlenmiştir. Göz takip cihazı ile katılımcıların performansları kayıt altına alınmıştır. Dört farklı uyaran ile test edilen katılımcıların, ön test sonuçlarına göre sadece elden hızlı şekilde atılan servislerin izlenme performansında anlamlı farklılık gözlenmiştir. Eğitim sonrasındaki ölçümlere göre, deney grubunun elden hızlı atılan servislere karşılık belirgin bir gelişme gösterdiği görülmüştür.
\end{abstract}

Anahtar kelimeler: Göz takibi, Masa Tenisi.

\section{Investigation the Effect of Multi ball Table Tennis Training on Visual Reaction Performance in Youths Aged 9-12}

\begin{abstract} has a direct effect on the sports performance. Improved visual attention, causes rapid and accurate reaction of the planned movement. In the concept of this study, two groups of participants have been examined with a table tenis attention paradigm. One of the groups have been trained about table tennis for 12 weeks. In each week 3 sessions were performed while the other group has not been trained. After

* Marmara Üniversitesi, Sağlık Bilimleri Enstitüsü, yekupi@hotmail.com

** Yrd. Doç. Dr., Marmara Üniversitesi, Spor Bilimleri Fakültesi, deniz.duru@marmara.edu.tr
\end{abstract}

Visual attention is related with our awareness level about the world around us. Visual attention requires selection of information and higher values of it enable us to react faster. It is obvious that visual attention 
the 12 weeks training session, the same paradigm has been applied to all participants. The paradigm consist the visual stimulation of four different categories. The table tennis services were performed by robot and a trainer with varying speeds grouped as fast and slow. The visual reactions were measured by eye tracker and the performance of the subjects have been computed. In the first measurements, a difference has been observed caused by the fast services that have been sent by the trainer while after the training period, trained group exhibited better performance to the fast services sent by the trainer.

Keywords: Eye tracker, table tennis

\section{GiRiş}

Sportif performansı etkileyen önemli bilişsel işlevsellerden biri dikkatdir. Sporcu, yarışma boyunca dikkatini doğru noktaya odaklayarak yüksek performansa ulaşabilir. İnsansda fiziksel becerilerdeki günlük değişiklik çok olmasada, bilişsel dikkat düzeyindeki oynamalar gözlemlenebilmektedir. Görsel dikkatin performansa doğrudan etki yapabildiği sporların başında masa tenisi gelmektedir. Görsel dikkate ek olarak masa tenisi branşında sporcuların dikkatini dağıtacak çok fazla unsur bulunmaktadır. Antrenman ve müsabaka esnasında sporcular uzun süre dikkatini aynı seviyede tutamayabilirler. Görsel dikkatin bir ölçütü olarak hareketli ve süratli nesnelerin gözlerimiz tarafından ne oranda takip edilebildiği bilgisi branşa özgü bir öznitelik olarak düşünülebilir.

Görsel dikkat, farklı branş sporcuları ve sedanterler arasında farklılık gösterebilmektedir. Hızlı hareket eden rakiplere veya nesnelere karşı yapılan mücadelelerde sporcuların daha iyi bir performans ortaya koyması için baş ve boynunu çok hareket ettirmeden sadece gözleriyle takip etmelidir (Aksoyak ve ark 2005). Bu göz hareketlerinde hızlı fiksasyonu oluşarak yerinde müdahaleyi kolaylaştırır. Dikkat ve odaklanma süresi ise birlikte göz ve vücut koordinasyonunu da olumlu etkilediği için çoğu spor dalı için önem arz etmektedir.

Literatürde yapılan çalışmalarda, sağlık sorunu olmayan ve daha önce görsel tepki süresini geliştirebilecek herhangi bir spor veya aktiviteye katılmamış grup ile masa tenisi sporcularının görsel tepki süreleri karşılaştırılmış, 159 sağlıklı ve oyuncuya uygulanan çalışmada görsel tepki süresinin yaş ve vücut kitle indeksi ile ters ilişki içinde olduğu ortaya konmuştur (Mahesh ve ark 2013).

15-17 yaş grubu erkek ve bayan voleybol sporcularının smaçör-pasör mevkilerine göre görsel ve işitsel reaksiyon zamanlarını irdelemek ve farklılıklarını ortay koymak için yapılan araştırmada ise, Power Newtest 2000 cihazı kullanılmış her oyuncuya üçer defa ölçüm yapılmış ve yapılan değerlerin en iyi olanı değerlendirilmiştir. Araştırma sonucunda erkek pasör ve smaçörler arasında işitsel ve sağ el reaksiyon zamanında istatistiksel olarak anlamlı farklılık bulunmuştur (Binboğa, 2011). Dokuz erkek ve dokuz bayan eskrimcinin katıldığı, elit eskrimcilerde maksimal yüklenme yoğunluğunun görsel reaksiyon zamanı ile ilişkisinin araştırıldığ 1 bir çalışmada, katılımcılar pedal çevirirken kalp ritim hızları ölçülürken görsel reaksiyon zamanı test akışı 
devam ederken, Newtest reaksiyon ölçer ile dominant el test edilmiştir. Sonuçta maksimal yüklenme yoğunluğunun elit eskrim sporcularının görsel reaksiyon zamanı üzerinde olumsuz etkiye sahip olduğu görülmüştür. (Duvan ve ark 2010). Diğer bir araştırmada direkt temas içinde olan(voleybol, karate hentbol, basketbol) ve doğrudan bir temas-etkileşim olmayan(yüzme, atletizm, ve dans) gibi spor dallarıyla ilgilenen 127 sporcunun el-göz koordinasyonu bilgisayar ortamında TUD (Dynamic Tracking) ile ölçülmüş ve kayıt edilmiştir. Doğrudan temas içinde olan branşların sporcuları diğerlerine göre daha iyi el-göz koordinasyonuna sahip olduğu belirlenmiştir (Grigore, 2012).

Tenis antrenmanlarının görsel ve işitsel reaksiyon zamanına etkisinin incelendiği bir araştırmada, 8-10 yaşlarında 48 katılımcıdan (24 denek ve 24 kontrol) 12 hafta boyunca devam edilen tenis antrenmanlarının başında ve sonunda New Test 2000 cihazı kullanılarak el göz koordinasyonları ölçülmüştür. 8-10 yaş tüm denek gruplarında sağ-sol el görsel ve işitsel reaksiyon zamanlarının azaldığı görülmüştür (Yıldırım, 2011).

Optik reaksiyon zamanlarının spor dallarına göre karşılaştırılıp incelendiği bir çalışmada orta öğrenim ve yüksek öğrenim düzeyindeki (kayak, basketbol, voleybol, masa tenisi, güreş ve futbol) 123 erkek ve 77 bayan olmak üzere toplam 200 sporcu ölçülmüş ve voleybol branşının oyuncularının diğer branşların oyuncularına göre daha iyi optik reaksiyon süresine sahip olduğu ortaya çıkmıştır (Erzurumluoğlu ve Çalışkan, 1999).

Futbolcuların reaksiyon zamanlarının incelenmesi konu alan bir araştırmada 9-14 yaşları arasında spor yapan ve yapmayan toplamda 160 gönüllünün katıldığı çalışmada denek grubuna 16 hafta boyunca temel futbol antrenmanları gerçekleştirilirken kontrol grubuna hiçbir eğitim uygulanmamıştır. Her iki grubunda ön ve son testleri, NewTest 2000 cihazı kullanılarak yapılmıştır. 16 haftalık temel futbol eğitimi alan çocukların görsel reaksiyon zamanlarında olumlu bir iyileşmenin olduğu görülmüştür (Boyar, 2013).

Üniversite düzeyindeki 45 masa tenisi sporcusuna sekiz hafta boyunca, üç gruba üç farklı antrenman programının uygulandığı bir araştırmada, masa tenisi sporcularının görüş açısının ve el göz koordinasyonu antrenmanlarının oyuncuların performansı üzerindeki etkisi incelenmiştir. Birinci gruba el ve göz koordinasyonunu geliştirici antrenmanlar, ikinci gruba videolar izlettirilip ve o konu hakkında kitaplar okutturulmuş ve üçüncü gruba ise normal standart masa tenisi antrenmanları yaptırılmıştır. Antrenmanların sonunda birinci grubun el göz ve reaksiyon zamanlarının daha iyi olduğu ortaya çıkmıştır (Paul ve ark., 2011).

Masa tenisi sporcularında tercih edilmeyen el üzerine gerçekleştirilen beceri çalışmalarının, baskın olan elin performansı üzerinde olumlu etki yarattığı gösterilmiştir (Erdil ve ark., 2013).

Bu çalışmalara ek olarak, en az sekiz yıl deneyimi olan beşi eski tecrübeli beşi az tecrübeli toplam on antrenörün katıldığı araştırmaya tenis kortlarındaki göz hareketlerinin durumu ve antrenör davranışlarının incelenmesini konu alan çalışmada, her iki grubun antrenörlerinden servis atışı yapacak olan tenis oyuncularının servislerini izlemeleri istenmiştir. Eski tecrübeli antrenörlerin 
servis atı̧̧ı sırasındaki hatalara hemen odaklanabiliyorken aynı anda daha az göz sekmesi yaptıkları, az tecrübesi olan antrenörlerin ise daha fazla göz sekmesi yaparak servis atı̧sındaki hatalara çabuk odaklanmadığı görülmüştür. Göz takip cihazı kullanılarak yapılan çalışmada, göz hareketleri cihaz tarafından yüksek zamansal hassasiyetle kayıt edilmiş̧ir (Hernandez ve ark., 2006). Rodrigues ve ark. (2002) tarafından gerçekleştirilen bir çalışmada, çeşitli uyaranlarla masa tenisi servisinin atılması gereken yer belirtilmiş, ve göz takip cihazı ile reaksiyonlar kayıt edilmiştir. Aynı grubun bir diğer çalışmasında göz hareketliliğinin postüral sabitliğin üzerine olumlu etkisi olduğu ortaya koyulmuştur (Rodrigues ve ark., 2013).

Dikkat ve reaksiyon sürelerinin araştırıldığı çalışmaların bir çoğunda elit sporcuların veya yüksek performans gösteren kişilerin yapılan testlerde reaksiyon sürelerinin daha az olduğu gösterilmiştir. Karate-do sporcularına yönelik gerçekleşitirlen bir çalışmada ise, kişilerin verilen ödevde, görsel uyaranda karate sporuna yönelik puan getirecek harekete odaklanmaları istenmiştir. Yapılan araştırmada karateciler kontrol grubundan görsel parametreler açısından farkll1ıklar göstermiştir (Balcıŏlu ve ark, 2014).

$\mathrm{Bu}$ çalışmadaki amaç ise, yapılacak 12 haftalık masa tenisi eğitimi ile, masa tenisine özgü hazırlanmış olan test paradigmasında yapılacak olan göz-performans ölçümlerinde iyileşmenin olup olmayacağının incelenmesidir.

\section{MATERYAL VE METOD}

\section{Çalışma Grubu}

İstanbul Sultan Gazide Bulunan İstanbul Büyükşehir Belediyesi Spor Kulübü’nde 2016 yllında masa tenisi sporuna başlayacak olan 40 erkek katılımcı rastgele örnekleme ile seçilmiştir. Hiçbir yetenek seçimi testine tabi tutulmadan ve hiç masa tenisi oynamamış 9-12(minik) yaş aralığından seçilen 20 katılımcı denek grubunu, diğer 20 katılımcı ise kontrol grubunu oluşturmuştur.

\section{Veri Toplama Araçları}

Çalışmada veri toplama aracı olarak Göz takip cihazı (eye tracker) kullanılmıştır. Uzman antrenör tarafından yavaş (84 adet) ve hızlı (144 adet) olarak iki farklı şekilde atılan masa tenisi servisleri, karşılayacak kişinin göz hizasını orta nokta olarak belirlenmiş şekilde video kayıtı altına alınmıştır. Benzer şekilde, servis atan masa tenisi robotu ile aynı sayıda uyaran kayıt edilmiştir. Video uyaranın toplam süresi 10 dakika olarak gerçekleştirilmiştir. SMI marka göz takip cihazı $60 \mathrm{~Hz}$ veri toplama frekansı ile, göz hareketlerini ölçmek için kullanılmıştır. 


\section{Verilerin Toplanması}

9-12 (minik) yaş arası ve ön-test-son-teste katılmak için protokolü, velileri tarafından imzalanmıştır. Bu çalışma bilimsel ve etik yönden Marmara Üniversitesi Etik Kurulu tarafından 28.03.2016-19 tarih ve 252 protokol numarasıyla onanmıştır. Göz takip cihazı ekranın altında göz hizasında ekranı ortalayacak şekilde yerleştirilerek, ekran ile kişi arasında ki mesafe 45-75 cm olacak şekilde ayarlandı. Deney paradigmasına ait bir görüntü Şekil 1'de görülmektedir.
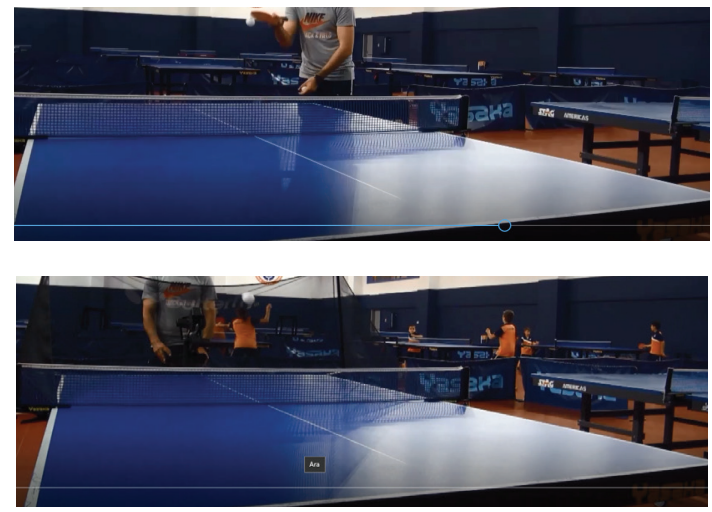

Şekil I. El ile atılan servis ve robot tarafından gönderilen servislerin anlık görüntü örnekleri.

\section{Verilerin Analizi}

Çalışma kapsamında gerçekleştirilen ön ve son testlerde, göz hareketleri her uyaran için izlenerek, atılan servislerde topun izlenip izlenmediği sayılmıştır. Başarılı izlenen servisler için performans skoru bir yükseltilmiş, başarısız izlenenler için skorda herhangi bir değişiklik yapılmamıştır. Ön ve son testler arasındaki performans farkları, iki grup arasındaki farklılı̆̆ karşılaştırmak için kullanılmıştır. Parametrik olmayan iki bağımsız örneklem testi ile gruplar arası farklar analiz edilmiştir. Deney ve kontrol grubuna ait birer denek son ölçümlere katılamadıkları için çalışmadan çıkarılmışlardır.

\section{BULGULAR}

Deney ve kontrol gruplarının yaş ortalamaları sırasıyla 11 ve 10.25 sene iken, standart sapmaları 1.5 sene olarak hesaplanmış ve Deneklerin ve kontrollerin yaşları arasında anlamlı bir farklılık bulunmamıştır ( $\mathrm{p}=0.084)$. Katılımcıların spor yaşı deney grubu için ortalama 1.75 , standart sapması 1.4 sene iken kontrol grubu için ortalama 1.6 sene, standart sapma 0.9 sene olmak üzere, iki grup arasında spor yaşı bakımından farklılık istatistiksel olarak anlamlı değildir $(\mathrm{p}=0.73)$. 
Deney ve kontrol grubunu oluşturan bireyler daha önce masa tenisi eğitimi almamıştır. Tablo l'de dört farklı uyaran ile gerçekleştirilen testler sonucunda, deney ve kontrol grubu katılımcıları arasında görsel reaksiyon performansı kriteri bağımsız örneklem testi ile incelenmiştir.

Tablo I. Deney ve kontrol grubu ön, son test sonuçları ve son test ile ilk test arasındaki gelişimin bağımsız örneklem (Mann-Whitney U) ile karşılaştırılması.

Grup İstatistiği

\begin{tabular}{|c|c|c|c|c|c|c|}
\hline & Grup & $\mathrm{N}$ & Ortalama & Std. Sapma & $\begin{array}{c}\text { Ortalama } \\
\text { Siralama }\end{array}$ & $\mathrm{P}$ \\
\hline \multirow{2}{*}{ ROBOT Yavaş İlk } & Deney & 19 & 54,89 & 10,187 & 20,21 & \multirow{2}{*}{0.383} \\
\hline & Kontrol & 19 & 51,11 & 15,709 & 18,79 & \\
\hline \multirow{2}{*}{ ROBOT Hızlı İlk } & Deney & 19 & 91,11 & 37,591 & 17,50 & \multirow{2}{*}{0.370} \\
\hline & Kontrol & 19 & 102,63 & 40,667 & 21,50 & \\
\hline \multirow{2}{*}{ ELDEN Yavaş İlk } & Deney & 19 & 61,37 & 14,611 & 16,68 & \multirow{2}{*}{0.458} \\
\hline & Kontrol & 19 & 66,00 & 22,608 & 22,32 & \\
\hline \multirow{2}{*}{ ELDEN Hızlı İlk } & Deney & 19 & 75,79 & 42,941 & 15,74 & \multirow{2}{*}{0.025} \\
\hline & Kontrol & 19 & 107,16 & 39,607 & 23,26 & \\
\hline \multirow{2}{*}{ ROBOT Yavaş Son } & Deney & 19 & 61,53 & 7,411 & 22,84 & \multirow{2}{*}{0.533} \\
\hline & Kontrol & 19 & 59,05 & 15,440 & 16,16 & \\
\hline \multirow{2}{*}{ ROBOT Hızlı Son } & Deney & 19 & 124,68 & 19,880 & 21,37 & \multirow{2}{*}{0.383} \\
\hline & Kontrol & 19 & 118,16 & 25,362 & 17,63 & \\
\hline \multirow{2}{*}{ ELDEN Yavaş Son } & Deney & 19 & 71,95 & 13,858 & 17,13 & \multirow{2}{*}{0.456} \\
\hline & Kontrol & 19 & 75,05 & 11,448 & 21,87 & \\
\hline \multirow{2}{*}{ ELDEN Hızlı Son } & Deney & 19 & 116,89 & 29,648 & 19,82 & \multirow{2}{*}{0.949} \\
\hline & Kontrol & 19 & 116,32 & 25,662 & 19,18 & \\
\hline \multirow{2}{*}{ Fark Robot Yavaş } & Deney & 19 & 6,6316 & 12,15278 & 20,71 & \multirow{2}{*}{0.830} \\
\hline & Kontrol & 19 & 7,9474 & 23,62549 & 18,29 & \\
\hline \multirow{2}{*}{ Fark Robot Hızlı } & Deney & 19 & 33,5789 & 40,67120 & 22,26 & \multirow{2}{*}{0.145} \\
\hline & Kontrol & 19 & 15,5263 & 33,78916 & 16,74 & \\
\hline \multirow{2}{*}{ Fark Elden Yavaş } & Deney & 19 & 10,5789 & 19,31124 & 20,26 & \multirow{2}{*}{0.822} \\
\hline & Kontrol & 19 & 9,0526 & 22,20979 & 18,74 & \\
\hline \multirow{2}{*}{ Fark Elden Hızlı } & Deney & 19 & 41,1053 & 41,18508 & 23,68 & \multirow{2}{*}{0.020} \\
\hline & Kontrol & 19 & 9,1579 & 39,61378 & 15,32 & \\
\hline
\end{tabular}

\section{TARTIŞMA}

Dört farklı uyaran ile test edilen katılımcıların, ön test sonuçlarına göre sadece elden hızlı şekilde atılan servislerin izlenme performansında anlamlı farklılık gözlenmiştir. Kontrol grubu üyeleri denek grubu üyelerine göre yüksek performans göstermişlerdir ( $p=0.025)$. Deneklerin seçimi rastgele gerçekleştirildiğinden ve tüm katılımcıların daha önce masa tenisi antrenmanı yapmadıklarından dolayı gözlenen bu farklılığın herhangi bir faktöre bağlı olmadığı düşünülebilir. 
Çok top antrenmanı gerçekleştiren deney grubu üyeleri ile antrenmanı gerçekleştirmeyen kontrol grubu üyelerinin, eğitim sonrasında gerçekleştirdiği son ölçüm sonuçlarının mutlak değerlerine göre, iki grubun son ölçümleri arasında farklılık gözlenmemiştir. Buna karşın, kontrol grubunun ve deney grubunun performans gelişimi son ölçümlerden ilk ölçümlerin farkının hesaplanmasıyla incelendi. Robot tarafından atılan servislerin incelenmesinde, fark, yavaş atılan servislere verilen reaksiyon için iki grupta da birbirine yakın iken, hızlı atılan servislerde çok top antrenmanı uygulanan grup lehine yüksek artış göstermiştir. Her iki farkta istatistiksel olarak anlamlılık değerlerine ulaşamamıştır. El ile kullanılan servislere verilen reaksiyonda ise, robot ile atılan servislere verilen cevaplarla uyumlu olarak, yavaş servislerde fark benzer şekilde artış göstermişken, hızlı servislere verilen cevapta denek grubu kontrol grubuna göre anlamlı derecede yüksek performans göstermiştir $(\mathrm{p}<0.02)$.

Bu bulgular ışığında, çok top antrenmanı uygulanan denek grubunun el ile atılan hızlı servisleri izleme hassasiyetinde iyileşme olduğu görülmektedir.

Sporda, kişinin hareket planlamasında görsel uyaranlar önemli rol oynamaktadır. Özellikle top ile yapılan sporlarda topun takip edilmesi ve hatta topun gideceği izin öngörülmesi büyük önem taşımaktadır (Land, 2000).

\section{SONUÇ ve ÖNERILER}

Robot tarafından atılan servislerin incelenmesinde, fark, yavaş atılan servislere verilen reaksiyon için iki grupta da birbirine yakın iken, hızlı atılan servislerde çok top antrenmanı uygulanan grup lehine yüksek artış göstermiştir. Her iki farkta istatistiksel olarak anlamlılık değerlerine ulaşamamıştır. El ile kullanılan servislere verilen reaksiyonda ise, robot ile atılan servislere verilen cevaplarla uyumlu olarak, yavaş servislerde fark benzer şekilde artış göstermişken, hızlı servislere verilen cevapta denek grubu kontrol grubuna göre anlamlı derecede yüksek performans göstermiştir ( $\mathrm{p}=0.02)$. Bu bulgular ışı̆̆ında, çok top antrenmanı uygulanan denek grubunun el ile atılan hızlı servisleri izleme hassasiyetinde iyileşme olduğu görülmektedir.

Sporun çeşitli branşlarında yapılan çalışmalar, göz hareketlerinin gerek sabitlenme, gereksede anlık hareket bakımından önemli bilgiler içerdiği ve bu parametrelerin yapılan çeşitli eğitimlerle geliştirilebildiğini göstermektedir. Çalışmamızın devamı niteliğinde, farklı katılımcı gruplarına uygulanacak eğitimlerle performans farklılıklarının izlenmesi amaçlanmaktadır.

\section{Teşekkür}

Çalışma kapsamında kullanılan SMI marka göz takip cihazını temin ederek, kullanımımıza sunan Inter Bilgisayar Elektrik ve Elektronik San. Dış. Tic. Ltd. Şirketine katkılarından dolayı teşekkür ederiz. 


\section{KAYNAKLAR}

Aksoyak H, Süer C, Yılmaz A, Can Y. Farklı dallardaki sporcuların sakkadik göz hareketi verilerinin karşılaştırılması, Erciyes Üniversitesi Sağlık Bilimleri Dergisi. 2005;1: 1-5.

Balcioğlu T, Şahin D, Assem M, Selman SB \& Göksel Duru D, Analysis of gaze characteristics with eye tracking in elite athletes: A pilot study, Biomedical Engineering Meeting (BIYOMUT), 2014 18th National, DOI: 10.1109/BIYOMUT.2014.7026345

Binboğa E. Genç Voleybolcularda smaçör ve pasör mevki oyuncuları arasındaki Reaksiyon zamanlarının karşılaştırılması, Yüksek Lisans Tezi Ankara, 2011.

Boyar H. Futbol Branşına Katılan 9-14 Yaş Grubu Erkek Çocuklarının Işık Reaksiyon Zamanlarının Belirlenmesi. Yüksek Lisans Tezi Konya, 2013.

Duvan A, Toros T, Şenel Ö. Maksimal Yüklenme Yoğunluğunun Elit Türk Eskrimcilerin Görsel Reaksiyon Zamanları Üzerine Etkisi. Niğde Üniversitesi Beden Eğitimi Ve Spor Bilimleri Dergisi Cilt 4, Sayı 3, 2010 .

Erdil G, Ölçücü B, Kaya F, Sabrioğlu S, Kaya Y. The Effect of the Training with Recessive Hand on the hitting Percentage of Shots Performed with the Dominant Hand for Table Tennis Players, Nigde University Journal of Physical Education And Sport Sciences Vol 7, No 1, 2013

Erzurumlu A. Orta Ve Yükseköğretim Düzeyinde Kız Ve Erkek Sporcularda Optik Reaksiyon Zamanlarının Spor Branşlarına Göre Karşılaştırılması, Yüksek Lisans, Erzurum, 1999.

Grigore Ve ark. Characteristic Of İnstrumental Movements Eye Hand Coordination İn Sports. Procedia Social and Behavioral Sciences 33, 2012 193-197.

Hernandez M, Javier F, Romero A. Visual Behaviour Of Tennis Coaches İn Court And Video-Based Conditions, Revista Internacional De Ciencias Del Deporte International Journal Sport Science 2941, 5232, 005032006.

Mahesh k. Ve ark. A comparative Study Of Reaction Time İn Tennis Players And Healthy Controls, Amerika, 2013.

Michael F. Land, Peter McLeod, From eye movements to actions: how batsmen hit the ball, Nature Neuroscience 3, 1340 - 1345 (2000).

Paul M, Biswas K, Sandhu J. Role Of Sports Vision And Eye Hand Coordınation Traınıng in Performance Of Table Tennıs Players, Faculty Of Sports Medicine - Physiotherapy, Guru Dev Universty, Amritsar, Punjab, India.

Rodrigues S, Aguiar S, Polastri P, Godoi D, Moraes R, Barela J. Effects Of Saccadic Eye Movements On Posrural Control Stabilization. Motriz Rio Claro, V.19 n.3, 2013.

Rodrigues S, Vıckers J, Williams A. Head, Eye And Coordination İn Table Tennis. Journal Of Sports Sciences, 20, 187-200, 2002.

Yıldırım i, Karagöz, Ş, Ocak Y. 8-10 Yaş Kız çocuklarında 12 Haftalık Tenis Antrenmanlarının Görsel Ve İşitsel Reaksiyon Zamanına Etkisinin İncelenmesi. Niğde Üniversitesi Beden Eğitimi Ve Spor Bilimleri Dergisi Cilt 5, Sayı 3, 2011. 